\title{
Lateral Orbitotomy for Cavernous Malformation: A Case Report with Technical Consideration
}

\author{
Haroon $\mathrm{K}^{1}$, Taher $\mathrm{T}^{2}$, Alamgir $\mathrm{A}^{3}$, Huq $\mathrm{N}^{4}$, Haq $\mathrm{MRU}^{5}$, Hossain $\mathrm{SS}^{6}$ \\ Conflict of interest: There is no conflict \\ of interest relevant to this paper to \\ disclose. \\ Funding Agency: was not funded by \\ any institute or any group. \\ Contribution of the authors: $1,3,4$ \\ were involved in care of the patient. 2 \\ manuscript preparation \\ Data collection-

\begin{abstract}
:
Cavernoma is benign tumour of the orbit. It results in proptosis, visual disturbance, diplopia and ptosis of the eye. It is amenable to surgery and this results in complete after surgical removal without recurrence. We report a case of right orbital cavernoma in a female, who presented with non-pulsatile painless proptosis, slight ptosis and double vision while looking at the right side. Her MRI revealed that she had a cavernoma of the right orbit. She was operated by the lateral orbitotomy. This easily removed the tumour, cosmetically acceptable and she became symptom free.
\end{abstract}

Scalp block with anaesthesia-

Editorial formatting-

Copyright: @2020bang.BJNS published by BSNS. This article is published under the creative commons CC-BY-NC license. This license permits use distribution (https://creativecommons. orgf/licences/by-nc/4-0/)reproduction in any medium, provided the original work is properly cited and is not used for commercial purposes.

Received: 09.08.19 Accepted: 16.12 .19
Key Words: Cavernous malformation, lateral orbitotomy, proptosis

Abbreviations: NF-Neurofibromatosis

Bang. J Neurosurgery 2020; 10(1): 102-105

\section{Introduction:}

Orbital cavernomas are the most frequent intraconal, intraorbital primary tumor in adults followed by capillary hemangiomas, lymphangiomas, and hemangiopericytomas. They represent $4 \%$ of all orbital tumors and $9-13 \%$ of all intracranial cavernomas ${ }^{1}$.

Kennedy had reported of 820 cases of orbital tumours in 1984. Of these $72(8.8 \%)$ were classified as vascular lesions. On further breakdown, only 14 cases were cavernous haemangioma ${ }^{2}$.

Although not true neoplasms, cavernous mal-formations are the most common benign orbital mass in adults. Patients with cavernous malformations are usually middle-aged adults (mean age, 43-48 years), and there is a female predominance among this patient population. Because these le-sions are slow growing, progressive painless proptosis is the most common clinical sign at patient presentation ${ }^{3}$. The typical clinical presentation is of mostly painless proptosis (mean 5$6 \mathrm{~mm}$ ), pain, lid swelling, diplopia, lump, and recurrent obstructed vision. Middle-aged women are the most commonly affected group, and the average duration from symptom onset to presentation is 4 years ${ }^{4}$. Easy to remember are the "Six P's" of orbital lesions: proptosis, pain, progression, pulsation, palpation, and periorbital changes ${ }^{5}$.

These are low-flow circumscribed lesions usually situated behind the globe, most commonly within the

1. Dr. Kaisar Haroon, Assistant Professor, Department of Neurosurgery, NINSH

2. Dr. Tania Taher, Assistant Professor, HFRC Medical College Hospital

3. Dr. Abdullah Alamgir, Associate Professor, Department of Neurosurgery, NINSH

4. Dr. Naila Huq, Associate Professor, Department of Neuropathology, NINSH

5. Dr. Md. Rakib-UI Haq, Medical Officer, Department of Neurosurgery, NINSH

6. Prof. Sk. Sader Hossain, Professor and Head, Department of Neurosurgery, NINSH

Address of Correspondence: Dr. Kaisar Haroon, Assistant Professor, Department of Neurosurgery, NINS Email:kaisar298@gmail.com, Phone +01711196577, ORCID: 0000-0002-3065-7877 
muscle cone. They do not usually interfere with visual acuity, except when the tumor lies in the orbital apex, where it may affect the optic nerve. Cavernous hemagiomas are readily amenable to surgical treatment and do not recur ${ }^{6}$.

In the differential diagnosis of orbital tumors, thyroid related orbitopathies, inflammatory processes, and pseudotumors can be misdiagnosed ${ }^{7}$.

CT scan and MRI are the main investigation modality. CT shows homogeneous soft tissue density, and may show small calcifications or phleboliths. MR shows isointense T1 signal, bright T2 signal, dark internal septations, and a dark circumferential rim that represents a fibrous pseudocapsule ${ }^{4}$.

Histopathologically cavernous angiomas are vascular anomalies, consisting of endothelium-lined caverns filled with blood at various stages of thrombosis and organization, and separated by a collagenous stroma devoid of mature vessel wall elements ${ }^{1}$.

There are four primary routes by which transorbital lesions can be reached: 1) the anterior orbitotomy without osteotomy; 2) lateral orbitotomy; 3) medial orbitotomy; and 4) a combination of the lateral and medial orbitotomies. The lateral approach was first proposed by Kronlein13 in 1889, and it was later modified by Berke ${ }^{8}$. Intraconal orbital tumors with welldemarcated margins and lateral localization may be removed with lateral orbitotomy ${ }^{9}$.

\section{Case report:}

A fifty years old non-diabetic, non-hypertensive woman came to us with history of progressive proptosis of the right eye a little ptosis and double vision of the right eye for about two years. She stated that her right eye gradually became prominent and it came out. There was no pain or pulsation. Her right upper eye lid also came down and she could not elevate the eye lid as before. Her diplopia was occasional, more during trying to look to the right side. This was slowly progressive. She has no history of trauma, fever or blurring of vision. On examination of the eyes, the right eye was pushed forward and medially, there was slight ptosis. Her visual acuity and color vision was normal. Other neurological examinations were normal.

Her MRI showed a tumour at the lateral and superior part of anterior orbit just above the eye ball. It was isointense in $\mathrm{T} 1$ and hyperintense in T2 with peripheral contrast enhancement.
The patient was operated upon through a right lateral orbitotomy. This begins with an S-shaped incision in the outer third of the eyebrow, which is directed downward and outward to the outer canthal level and continues posteriorly about $2 \mathrm{~cm}$. the skin and subcutaneous tissue were retracted. The lateral orbital rim was exposed. It was removed along with the lateral wall of the orbit with the help of drill and saw. The tumour was purple in color, well circumscribed and solid. It was about $2 \mathrm{~cm}$ in diameter. It was totally excised. The orbital rim and bone was placed and fixed with miniplate and screws. The wound was closed in layers. Her stitches were removed on $6^{\text {th }}$ POD and discharged on with advice for followup.

After surgery her movement of the right eye was normal, her diplopia had improved but her ptosis had not improved. On her followup after one month following surgery, her ptosis had improved.

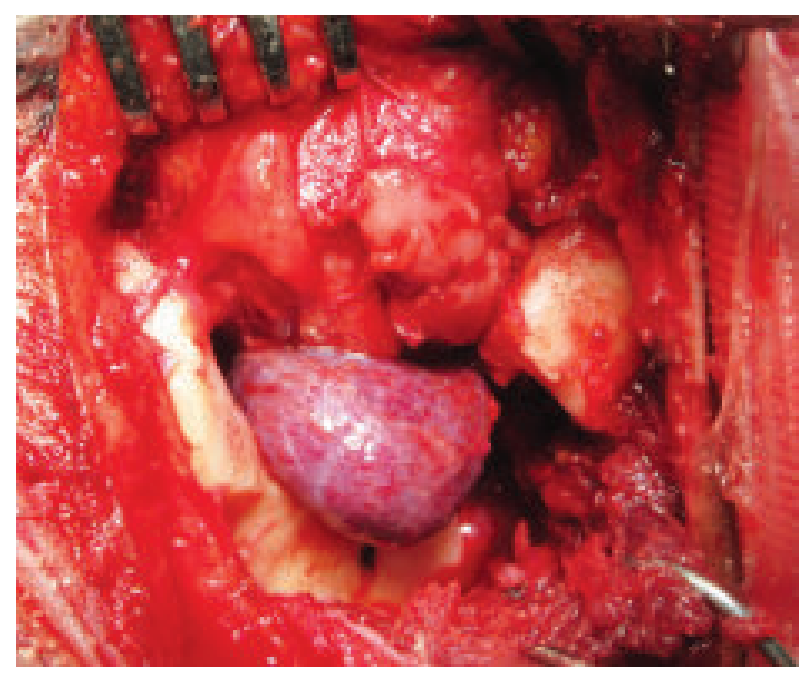

Fig.-1: Cavernoma coming out after removal of the lateral orbital rim and lateral orbital wall

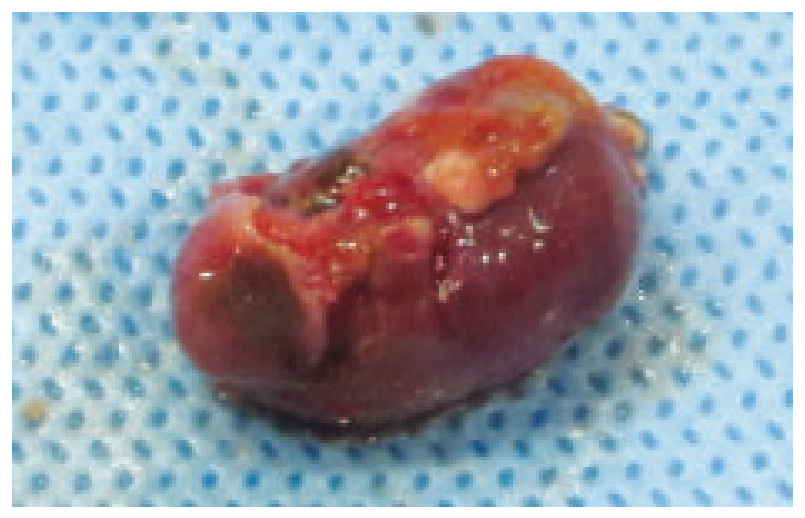

Fig.-2: Cavernoma after excision 


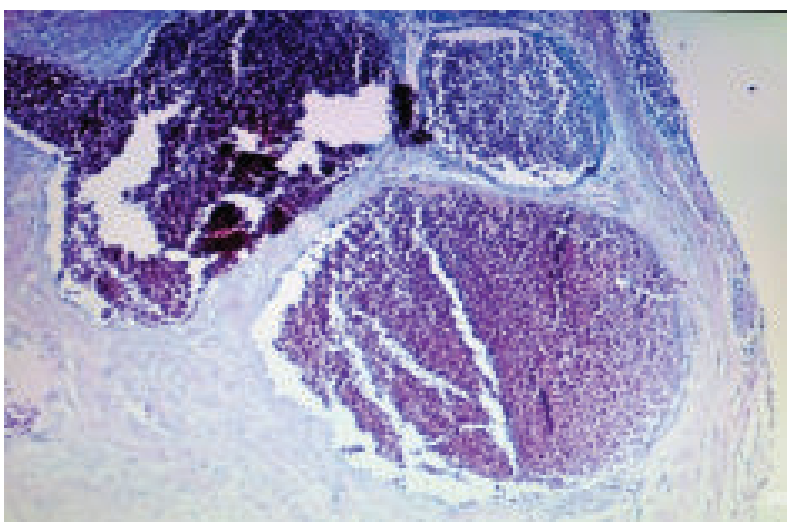

Fig.-3 : Histopathological photomicrograph. (haematoxillin and eosin stain)

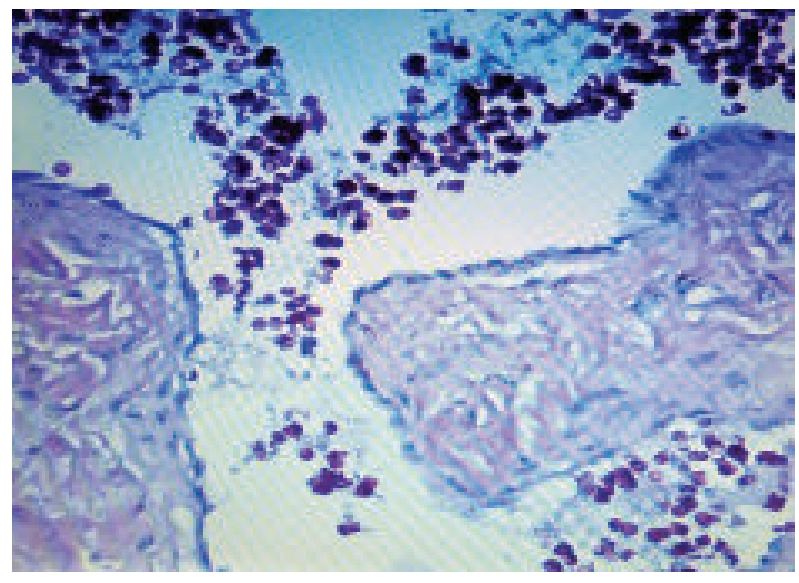

Fig.-4: High magnification of the Fig 3.

\section{Discussion:}

Orbital cavernoma is more common in female. It is also supported in the literatures ${ }^{1,10}$.Our patient was also female. The major presenting symptom is proptosis, resulting from the mass effect ${ }^{11}$. When the tumour is removed the symptoms improves as well. In our patient it took about a month for the ptosis to improve. Her diplopia had improved immediately following surgery.

Lateral orbitotomy provides excellent exposure of the temporal compartment of the orbit and it is indicated for well defined periorbital and intraconal tumors which are located lateral, dorsal and basal to the optic nerve It is useful for lacrimal gland tumors, retrobulbar lesions, such as cavernomas, and can be extended for posterior lesions ${ }^{12}$.

Lateral orbitotomy provides a wide surgical field in the orbit while providing an efficient access to superolateral cone. Lesions located superior, lateral and inferior to the orbital cone could be removed best via lateral orbitotomy ${ }^{9}$. Some surgeons preferred mass removal by using a lateral canthotomy and lateral orbital approach in 5 (35\%) patients with lesions located anteriorly and laterally ${ }^{7}$. The aim of this incision is to expose and resect the lateral wall and orbital rim ${ }^{5}$. This provides an excellent corridor for the lateraly placed tumours. The scar is small and it is cosmetic also. The tumours usually pop out of the orbit after the lateral orbitotomy. The lateral orbital rim, which needs to be removed for surgery, is fixed with miniplates and screws, so there is no disfigurement of the face.

In one study, there was only one case of cavernoma out of ten cases $^{9}$. In another study none of the seven (out of 74 cases) patients with an orbital lesion had worsened after operation: improvement of exophthalmos was seen in six patients, with improved visual acuity in five; the one asymptomatic patient remained intact ${ }^{10}$. Our patient had no visual symptoms. She had improved after the surgery. Her visual acuity had had not changed.

Lateral orbital approach is safe for the patients who had tumours at the lateral part of the orbit in Margalit et al series of 41 cases $^{13}$. Boari et al performed eight lateral orbitotomy cases and it was safe and acceptable to the patient ${ }^{1}$.

In 1941, W. E. Dandy, one of the pioneers of neurosurgery, postulated that all intraorbital lesions can be attacked by means of a transcranial procedure ${ }^{14}$. Today we reserve the transcranial approach for those lesions superior and medial to the optic nerve, especially if they involve the orbital apex. The lateral orbitotomy is widely accepted as the technique of choice for lesions confined to the lateral aspect of the orbit. First proposed by Kronlein in 1889, technical advances and modifications have made the lateral orbitotomy an effective, safe procedure ${ }^{14}$.

\section{Conclusion:}

Orbital cavernoma is a benign tumour of the orbit. This results in proptosis of the patient. Lateral orbitotomy is a safe and convenient approach for the removal of the laterally placed intraorbital cavernoma. It is cosmetically acceptable to the patient and technically easy for the surgeon.

\section{Reference:}

1. Boari N, Gagliardi F, Castellazzi P, Mortini P. Surgical treatment of orbital cavernomas: clinical and functional outcome in a series of 20 patients. Acta Neurochirurgica. 2011 March 01;153(3):491-8. 
2. Kennedy RE. An evaluation of 820 orbital cases. Transactions of the American Ophthalmological Society. 1984;82:134-57.

3. Tailor TD, Gupta D, Dalley RW, Keene CD, Anzai Y. Orbital neoplasms in adults: clinical, radiologic, and pathologic review. Radiographics. 2013;33(6):1739-58.

4. Khan SN, Sepahdari AR. Orbital masses: CT and MRI of common vascular lesions, benign tumors, and malignancies. Saudi Journal of Ophthalmology. 2012;26(4):373-83.

5. Mendoza-Santiesteban E, Mendoza-Santiesteban CE, Berazaín DAR, Freixas DRS, Alvarado LP, Garcia EP, editors. Diagnosis and surgical treatment of orbital tumors. Seminars in ophthalmology; 2010: Taylor \& Francis.

6. Darsaut TE, Lanzino G, Lopes MB, Newman S. An introductory overview of orbital tumors. Neurosurgical focus. $2001 ; 10(5): 1-9$.

7. Istemen I, Millet H, Gezercan Y, Afser KA, Okten Al. Orbital tumors: An analysis of fourteen cases. Journal of Turgut Ozal Medical Center. 2018;25(4).

8. Cockerham KP, Bejjani GK, Kennerdell JS, Maroon JC. Surgery for orbital tumors. Part II: transorbital approaches. Neurosurgical focus. 2001;10(5):1-6.
9. Okay O, Daglioglu E, Akdemir G, Dalgic A, Uckun O, Atasoy $\mathrm{S}$, et al. Lateral orbitotomy approach to orbital tumors: report of 10 cases. Turkish neurosurgery. 2010;20(2):167-72.

10. Acciarri N, Padovani R, Giulioni M, Gaist G, Acciarri R. Intracranial and orbital cavernous angiomas: A review of 74 surgical cases. British Journal of Neurosurgery. 1993;7(5):529-39.

11. Parashkevova B, Balabanov C, Stateva D. Orbital Tumors-Clinical Cases Presentation. Journal of IMABAnnual Proceeding (Scientific Papers). 2007;13.

12. Schick U, Unterberg A. Surgical Approaches to the Orbit. In: Quiñones-Hinojosa A, editor. Schmidek \& Sweet Operative Neurosurgical Techniques: Indications, Methods, And Results. 6 ed. Philadelphia: Saunders, an imprint of Elsevier Inc; 2012. p. 604-7.

13. Margalit N, Ezer H, Fliss DM, Naftaliev E, Nossek E, Kesler A. Orbital tumors treated using transcranial approaches: surgical technique and neuroophthalmogical results in 41 patients. Neurosurgical focus. 2007;23(5):E11.

14. Scheuerle AF, Steiner HH, Kolling G, Kunze S, Aschoff A. Treatment and long-term outcome of patients with orbital cavernomas. American Journal of Ophthalmology. 2004 2004/08/01/;138(2):237-44. 